\title{
Paxillus involutus Forms an Ectomycorrhizal Symbiosis and Enhances Survival of PtCOMT-modified Betula pendula in vitro
}

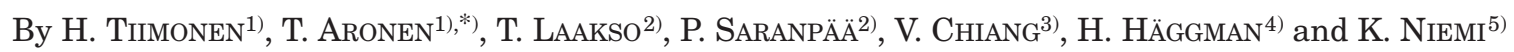

(Received 24 $4^{\text {th }}$ April 2007)

\begin{abstract}
The ability of the PtCOMT (caffeate/5-hydroxyferulate $O$-methyltransferase from Populus tremuloides L.) modified Betula pendula Roth. lines to form symbiosis with an ectomycorrhizal (ECM) fungus Paxillus involutus Batsch Fr. was studied in vitro. Lignin precursor gene PtCOMT was introduced into two $B$. pendula clones under the control of the cauliflower mosaic virus $35 \mathrm{~S}$ promoter or the promoter of the sunflower polyubiquitin gene $U b B 1$. Of the four transgenic lines, one 35SPtCOMT line (23) had a decreased syringyl/guaiacyl $(\mathrm{S} / \mathrm{G})$ ratio of root lignin, and two UbB1-PtCOMT lines (110 and 130) retarded root growth compared to the control clone. Both control clones and all transgenic lines were able to form ECMs with P. involutus, but the transgenic lines differed from the controls in the characteristics of the ECMs. The number of lateral roots covered with fungal hyphae and/or development of a Hartig net $(\mathrm{HN})$ were reduced in line 23 with a decreased $\mathrm{S} / \mathrm{G}$ ratio, and in lines 110 and 130 with slower root formation and changed root morphology, respectively. However, line 23 benefited more from the inoculation in lateral root formation than the control, and in lines 110 and 130 the percentage of viable plants increased most due to inoculation. The results show that $B$. pendula plants genetically transformed with the lignin gene PtCOMT could form mycorrhizal symbiosis regardless of changes in either the root $\mathrm{S} / \mathrm{G}$ ratio or development. The benefits of the symbiosis were variable even in the closed in vitro system, and dependent on the clone or transgenic line and the ECM fungal symbiont.
\end{abstract}

Key words: Betula pendula, COMT, ecological impacts of gmtrees, ectomycorrhiza, lignin modification, Paxillus involutus.

\section{Introduction}

Trees support a myriad of organisms and, in many cases, are key organisms with diverse interactions in the forest ecosystem. Ectomycorrhizas (ECMs) are symbiotic interactions between certain root fungi and most temperate and boreal forest trees, including many economically important species of the families Pinaceae,

1) Finnish Forest Research Institute, Punkaharju Research Unit, Finlandiantie 18, FIN-58450 Punkaharju, FINLAND.

2) Finnish Forest Research Institute, Vantaa Research Unit, Jokiniemenkuja 1, FIN-01301 Vantaa, FINLAND.

3) Department of Forestry, College of Natural Resources, Campus Box 7247, 2500 Partners II Bldg, North Carolina State University, Raleigh, NC 27695-7247, USA.

$\left.{ }^{4}\right)$ Department of Biology, University of Oulu, PO Box 3000, FIN-90014 Oulu, FINLAND.

${ }^{5}$ ) Department of Applied Biology, University of Helsinki, PO Box 27, FIN-00014 Helsinki, FINLAND.

*) Corresponding author: Doc. TUIJA ARonen. Tel: +358-10-211 4233, Fax: +358-10-211 4201, E-mail: tuija.aronen@metla.fi
Betulaceae and Fagaceae (SMITH and READ, 1997). Trees are highly dependent on the ECM fungi for nutrient and water acquisition (LINDAHL et al., 2002), and ECM fungi can also protect host trees against both biotic (MORIN et al., 1999) and abiotic stress (JENTSCHKE et al., 1999).

Paxillus involutus (Batsch) Fr. is a common ECM fungus forming a symbiosis with a large number of tree species including Betula pendula. In the ECM symbiosis between $P$. involutus and B. pendula (BRUN et al., 1995; LE QUÉRÉ et al., 2005) lateral roots are rapidly enclosed by the hyphal mantle and thus isolated nutritionally from the soil. In addition, the hyphae penetrate between epidermal cells and form a highly branched Hartig net at the nutrient exchange interface. During mycorrhiza formation the epidermal cells of lateral roots extend radially, which has been suggested to increase the surface contact between the symbionts (BRUN et al., 1995). The distinct stages in the ECM development between $B$. pendula and $P$. involutus are covered by numerous changes in gene expression in both symbionts (JOHANSSON et al., 2004; LE QUÉRÉ et al., 2005; MOREL et al., 2005), including the genes related to lignin biosynthesis in B. pendula (LE QUÉRÉ et al., 2005).

Lignin, one of the main components of cell walls, is a chemically stable hydrophobic phenolic heteropolymer which is needed for structural integrity, water resistance in vascular xylem and protection against invading micro-organisms (BAUCHER et al., 1998). Lignin precursor biosynthesis occurs in the cytoplasm, and the polymerisation of monolignols producing hydroxyphenyl $(\mathrm{H})$, guaiacyl (G) and syringyl (S) units occur in the cell wall. In angiosperms the main monomers are $\mathrm{G}$ and $\mathrm{S}$ units (SARKANEN and Hergert, 1971; Higuchi, 1985). Based on the 5-aromatic position of $\mathrm{S}$ units not available for strong carbon-carbon linkages, the content of S moieties is directly proportional to the solubility of lignin. The efficiency of wood pulping, for example, is dependent on the S monomer content in wood (CHIANG and FunAOKA, 1990; BAUCHER et al., 2003).

The intensive research on lignin biosynthesis and properties has continued for more than a century (SARKANEN and HERGERT, 1971; HIGUCHI, 1985), primarily because of the high economic impact of lignin extraction in the pulp and paper industry. The current model of lignin biosynthesis in angiosperms is proposed and discussed in several articles and reviews (BOERJAN et al., 2003; HofFMAN et al., 2004; Li et al., 2006). Additional information has been obtained from studies on natural lignin mutants and on plants genetically transformed with lignin precursor genes (ANTEROLA and LEWIS, 2002; Li et al., 2006). The lignin-modified trees have provided new perspectives on the genetic regulation of the 
amount and composition of lignin (HALPIN and BOERJAN, 2003). They are also considered to have good potential for tree breeding purposes or for multi-varietal forestry to provide improved raw wood for the pulp and paper industry (BAUCHER et al., 2003).

In respect of the numerous functions of lignin, there are various ways modified lignin might affect biological interactions, including effects on herbivory and defence responses against pathogens, decomposition of gm-material, and symbiotic interactions with mycorrhizal fungi (HALPIN et al., 2007). There are only a few reports on the ecological interactions of the lignin-modified trees in vivo (PILATE et al., 2002) or in vitro (TIIMONEN et al., 2005, SEPPÄNEN et al., 2007). The aim of the present work was to study the effects of lignin modification on the tree's interaction with ECM fungus. We produced four transgenic lines by introducing PtCOMT gene into two $B$. pendula clones and investigated their ability to form ECM symbiosis with $P$. involutus in vitro. This system was used because it is highly important to characterize a specific interaction between the certain line and the fungal strain before multiple biotic interactions in vivo are included in the research.

\section{Materials and Methods}

\section{Plant material}

Genetically modified Betula pendula Roth. lines were produced by introducing the PtCOMT (caffeate/5hydroxyferulate $O$-methyltransferase) gene originating from Populus tremuloides L. (Bugos et al., 1991) into B. pendula clones A and E5396, as described by ARONEN et al. (2003) and Timmonen et al. (2005). The PtCOMT gene was driven either by the cauliflower mosaic virus (CaMV) 35S promoter or by the promoter of the sunflower polyubiquitin gene UbB1 (BINET et al., 1991a; 1991b). Both gene constructs also contained the selective marker neomycin phosphotransferase II (nptII) gene driven by the CaMV $35 \mathrm{~S}$ promoter. Transgenic 35S-PtCOMT line 23 and UbB1-PtCOMT lines 65 and 130 originating in $B$. pendula clone A contained several copies of the transgene (ARONEN et al., 2003; TIIMONEN et al., 2005), and a similar result was obtained with

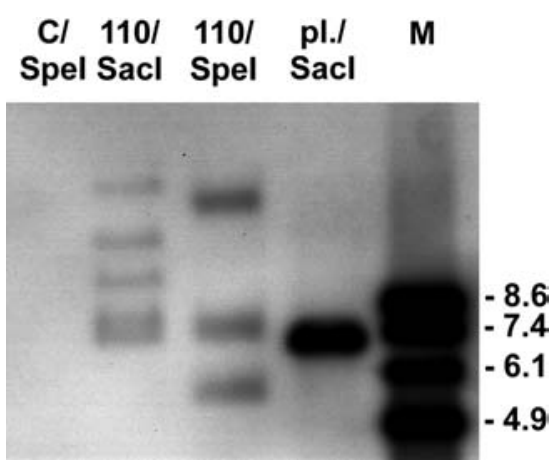

Figure 1. - Southern hybridisation of the UbB1-PtCOMT line 110 and the control clone E5396 (C). For the analysis, 11-12 $\mu \mathrm{g}$ of the total genomic DNA was digested with $S a c I$ or SpeI, separated in $0.8 \%$ agarose gel, transferred to a nylon membrane and hybridised with UbB1-PtCOMT probe according to ARONEN et al. (2003) and Timmonen et al. (2005). pl. UbB1-COMT plasmid, $M$ molecular weight marker.
UbB1-PtCOMT line 110 originating in clone E5396 (Fig. 1). The non-transformed micropropagated plants of both A and E5396 clones were used as controls.

Formation of the ECM interaction was studied in vitro using micropropagated $B$. pendula plants representing control clone A and its transgenic lines 23, 65 and 130, as well as control clone E5396 and its transgenic line 110. For the experiment, the plants were multiplied on Woody Plant Medium (WPM) (LLOYD and McCown, 1980) containing $2.2 \mu \mathrm{M}$ benzyladenine (BA) and 2.85 $\mu \mathrm{M}$ indole-3-butyric acid (IBA) by subculturing every third week. Multiplication of the transformants was carried out on a medium containing $200 \mathrm{mg} / \mathrm{l}$ kanamycin. For rooting, the shoots were transferred onto hormone-free WPM for 4 weeks. After the rooting period, the clones and lines differed from each other both in the number of adventitious roots and in subsequent root growth. Line 110 was inferior in adventitious root production compared to clone E5396, and the roots of line 130 were substantially shorter than those of clone A. Multiplication and rooting took place under a 16/8 h light/dark photoperiod with a light intensity of 85-114 $\mu \mathrm{E} \mathrm{m}^{-2} \mathrm{~s}^{-1}$ generated by cool white lamps (Airam L36W-642 Airam, Helsinki, Finland) at $24^{\circ} \mathrm{C}$.

\section{Fungal material}

The ECM fungus Paxillus involutus (Batsch) Fr. was isolated from under an Abies sp. stand in Punkaharju, Finland $\left(61^{\circ} 48^{\prime} \mathrm{N}, 2^{\circ} 19^{\prime} \mathrm{E}\right)$ in September 2001. The strain was deposited in the culture collection of the Punkaharju Research Unit, Finnish Forest Research Institute, by subculturing the mycelium on MelinNorkrans (mMN1) agar medium ( $\mathrm{pH}$ 5.8) (MARX, 1969) modified by HEINONEN-TANSKI and HolOPAINEN (1991). Our preliminary experiment established that the fungal strain was able to form ECMs with $B$. pendula in vitro (data not shown).

\section{Inoculation of Betula pendula in vitro plants with Paxillus involutus}

Petri dishes, $14 \mathrm{~cm}$ in diameter, were filled with $75 \mathrm{ml}$ of mMN2 (MARX, 1969) agar medium ( $\mathrm{pH}$ 5.7) modified by NiEMI et al. (2002). The concentration of glucose in the medium was low, $1.1 \mathrm{mM}$, in order to induce the formation of the mycorrhizal interaction. The surface of the agar was covered with a sterile moist filter paper (SCHLEICHER and SCHUELL, 595). An individual rooted in vitro plant was placed horizontally on the filter paper and the roots were kept separate. The plants were inoculated with $P$. involutus by placing three mycelial agar plugs, $5 \mathrm{~mm}$ in diameter and cut from the margin of the 8 -week-old culture, close to the root system. In non-inoculated cultures, sterile agar plugs were substituted for the fungal mycelium. The roots and mycelia were covered with a sterile, moist, semicircular filter paper and protected from light by a brown filter paper attached to the dish lid. The dishes were placed in racks leaning at an angle of $70^{\circ}$, at bench level in the culture room where they were subjected to a $16 / 8 \mathrm{~h}$ light/dark photoperiod at $22^{\circ} \mathrm{C}$ with a light intensity of $133-136 \mu \mathrm{E} \cdot \mathrm{m}^{-2} \cdot \mathrm{s}^{-1}$ provided by cool white lamps (Airam). The plants were grown together with the fungus for 8 weeks. The experi- 
ment consisted of 18-20 replicates per treatment. At the time of harvest, the number of viable plants per treatment was counted. The number of adventitious and lateral roots was also noted. The shoot and root samples were dried at $60^{\circ} \mathrm{C}$ for $48 \mathrm{~h}$ and then stored at room temperature until used for the dry mass determination at $103{ }^{\circ} \mathrm{C}$ for overnight. The number of lateral roots covered with the fungal hyphae was evaluated under a stereo microscope, and samples of roots with the fungal hyphae were taken for examination by light microscopy.

\section{Light microscopy}

The roots covered by the fungal hyphae, as well as non-inoculated lateral roots sampled from 3- to 4-weekold plants prior to the experiment, were analysed by light microscopy. The roots were prefixed in $0.1 \mathrm{M}$ phosphate buffer ( $\mathrm{pH} 7.0$ ) containing $2.5 \%(\mathrm{v} / \mathrm{v})$ glutaraldehyde (Sigma-Aldrich) for one day and then postfixed for four hours in 1\% osmium tetroxide (Sigma-Aldrich) and dehydrated in a graded ethanol series. The root samples were infiltrated and embedded in Ladd's LX 112 resin. The sections were cut with an LKB III Ultratome and stained with toluidine blue (Merck). Root sections from 4 to 15 in vitro plants per clone or line were examined under a light microscope (Olympus BX51) equipped with Olympus U-TV0.35XC camera.

\section{Root lignin analyses}

For the analysis of syringyl (S) and guaiacyl (G) monomers of root lignin, non-inoculated and inoculated in vitro roots were ground to a fine powder and extracted once with acetone, ethanol and water in a Soxhlet apparatus. S and G monomers were determined on 0.25 , 3 or $5 \mathrm{mg}$ extractive-free lignin of in vitro roots by thioacidolysis (ROLANDO et al., 1992). The gas chromatography-mass spectrometry (GC-MS) analyses were performed according to TIIMONEN et al. (2005). The analyses were repeated four times except in the case of non-inoculated roots of control clone $\mathrm{A}$ and lines 130 and
110 , on which only one determination was performed due to the small amount of material available for the analyses.

Due to the limited amount of in vitro roots available for $\mathrm{S} / \mathrm{G}$ analyses, the root samples from the 2- to 3-yearold non-inoculated plants growing in the greenhouse and representing the same clones and lines that were used in the in vitro experiment were also analysed. The greenhouse-grown plants are described in more detail in ARonen et al. (2003). Prior to analysis, the roots were rapidly washed with water, debarked and cut into 1-3 cm sections. The sections were then treated as the in vitro roots except that two extractions per line/clone were performed. In the $\mathrm{S} / \mathrm{G}$ analysis, $5 \mathrm{mg}$ of extractivefree lignin was used and 2-3 determinations per sample were performed in the same way as for the in vitro roots.

\section{Statistical analyses}

Comparison between the non-inoculated and inoculated plants within the clone or line, as well as comparison between clone E5396 and its transgenic line 110, were performed with a parametric $t$-test (in case that both data to be compared passed the test of normality) or a non-parametric Mann-Whitney U-test (in case that at least one of the data to be compared did not pass the test of normality). The Kruskall-Wallis-test combined with the Mann-Whitney U test with a Bonferroni correction was used when clone A was compared to its transgenic lines. Arcsin square transformation was applied to the data of the proportion (\%) of lateral roots covered by the fungal hyphae. The SPSS 13.0 statistical software was applied in the analyses.

\section{Results \\ Effects of Paxillus involutus on plant growth in vitro}

Inoculation with $P$. involutus increased the percentage of viable in vitro plants (Table 1). This was most clear in transgenic lines 130 and 110 with retarded root develop-

Table 1. - Effect of the ectomycorrhizal fungus Paxillus involutus on plant viability, shoot and root dry weight (DW) and root development of the Betula pendula control clones and PtCOMT lines in vitro. Values are mean \pm standard error of mean (SE) after 8 weeks of culture in the presence (in) or absence (non) of the fungus. The different letters following the values denote a significant $(P<0.05)$ difference between the non-inoculated and inoculated plants within the clone or line according to independent samples $t$-test or Mann-Whitney U-test. $n=$ number of plants at the beginning of the experiment.

\begin{tabular}{|c|c|c|c|c|c|c|c|c|c|c|c|c|}
\hline \multirow[t]{2}{*}{$\begin{array}{l}\text { Clone } \\
\text { Line }\end{array}$} & \multicolumn{2}{|c|}{$n$} & \multicolumn{2}{|c|}{$\begin{array}{c}\text { Number } \\
\text { of viable } \\
\text { plants }\end{array}$} & \multicolumn{2}{|c|}{$\begin{array}{l}\text { Shoot DW } \\
\text { mgtSE }\end{array}$} & \multicolumn{2}{|c|}{$\begin{array}{l}\text { Rool DWr } \\
\text { Ing }=S L\end{array}$} & \multicolumn{2}{|c|}{$\begin{array}{l}\text { Number ol advent itious } \\
\text { roots } \mathrm{SE}\end{array}$} & \multicolumn{2}{|c|}{ Number of lateral roots $\pm S t$} \\
\hline & notı & in & toon & it1 & non & int & non & in & non & in & non & its \\
\hline$\Lambda$ & 20 & 19 & 12 & 16 & $18.3=3.1^{: 1}$ & $28.5 \pm 3.5^{l}$ & $2.5 \pm 0.7^{n}$ & $3.7=0.5^{1 .}$ & $3.0 \pm 0.3^{i t}$ & $3.6 \pm 0.4^{\mathrm{it}}$ & $37.0 \pm 10.5^{4}$ & $53.1=6.2^{l r}$ \\
\hline 23 & 20 & 20 & 18 & 20 & $20.5 \pm 2.4^{3}$ & $29.5 \pm 1.6^{11}$ & $3.2 \pm 0.5^{4}$ & $4.2=0.3^{13}$ & $3.6 \pm 0.3^{11}$ & $3.4 \pm 0.3^{: L}$ & $51.6 \pm 9.3^{3}$ & $87.4=7.8^{1 r}$ \\
\hline 65 & 20 & 20 & 18 & 20 & $18.5 \pm 2.5^{: 1}$ & $28.5 \pm 2.0^{\mathrm{l}}$ & $2.3 \pm 0.3^{i n}$ & $3.7=0.4^{l}$ & $3.1 \pm 0.3^{1}$ & $2.9 \pm 0.2^{2}$ & $41.4 \pm 9.6^{\prime \prime}$ & $74.2 \pm 7.1^{1 .}$ \\
\hline 130 & 19 & 18 & 4 & 13 & $21.1 \pm 3.7^{3}$ & $22,1 \pm 1,7^{4}$ & $2.5 \pm 0.6^{4}$ & $2.8 \pm 0.8^{1}$ & $3.5 \pm 0.5^{4}$ & $3.7 \pm 0.4^{i}$ & $20.5 \pm 5.1^{4}$ & $29.5=2.9^{4}$ \\
\hline E5396 & 19 & 20 & 16 & 18 & $21.7 \pm 2.7^{\prime}$ & $28.0 \pm 1.2^{\mathrm{l}}$ & $4.7 \pm 0.8^{\prime \prime}$ & $6.5=0.6^{19}$ & $2.8 \pm 0.3^{i}$ & $2.6 \pm 0.2^{i t}$ & $120.1 \pm 30.5^{\mathrm{a}}$ & $106.3 \pm 13.9^{11}$ \\
\hline 110 & 20 & 20 & 6 & 11 & $16.0 \pm 2.1^{\mathrm{J}}$ & $18.7 \pm 2.4^{4}$ & $6.3 \pm 0.9^{\prime}$ & $7.4 \pm 1.5^{1}$ & $2.2 \pm 0.2^{1}$ & $1.9 \pm 0.3^{1}$ & $26.2 \pm 7.7^{\lrcorner}$ & $36.5=8.9^{4}$ \\
\hline
\end{tabular}


ment. In these lines the percentage of viable plants increased from $21 \%$ to $72 \%$ and from $30 \%$ to $55 \%$, respectively, as a response to inoculation.

The inoculated plants had significantly higher shoot dry weights compared to the non-inoculated plants in control clones A $(P=0.011)$ and E5396 $(P=0.041)$, as well as in transgenic lines $23(P=0.001)$ and 65 $(P<0.001)$. Among the non-inoculated clones and lines there were no differences in the shoot dry weights. Similarly, there was no significant difference in the shoot dry weight between inoculated control clone A and its transgenic lines 23, 65 and 130. In contrast, inoculated control clone E5396 had a significantly $(P=0.003)$ higher shoot dry weight than line 110 (Table 1).

The root dry weight of the inoculated plants was significantly higher compared to the non-inoculated plants in control clones A $(P=0.023)$ and E5396 $(P=0.043)$, and transgenic lines $23(P=0.023)$ and $65(P=0.007)$. When the control clones were compared with their transgenic lines, there was no difference in the root dry weight among the non-inoculated or inoculated plants (Table 1).

\section{Effect of Paxillus involutus on the number of adventitious and lateral roots}

The $B$. pendula in vitro plants had two to four adventitious roots at the beginning of the experiment, and the inoculation had no effect on the formation of adventitious roots. The number of adventitious roots did not differ between the control clones and the corresponding transgenic line/s when inoculated with $P$. involutus or grown without the fungus, i.e. also line 110 that at the beginning of the experiment had impaired adventitious root formation was able to develop new roots as the control clone E5396 (Table 1).
The formation of lateral roots increased significantly due to the inoculation in control clone $\mathrm{A}(P=0.018)$ and in lines $23(P=0.002)$ and $65(P<0.001)$. In control clone E5396, the high number of lateral roots (464) on one non-inoculated plant influenced the mean value of the non-inoculated plants. When inoculated with $P$. involutus, control clone A formed significantly fewer lateral roots than transgenic line $23(P=0.009)$, and more lateral roots than transgenic line $130(P=0.009)$ (Table 1). Clone E5396 formed more lateral roots than transgenic line 110 both in the absence $(P=0.015)$ and in the presence $(P=0.001)$ of $P$. involutus (Table 1$)$.

\section{Formation of ectomycorrhizas (ECMs)}

Both the control clones and transgenic lines were able to form ECMs with $P$. involutus. The characteristics of the ECMs varied, however, between the non-transformed control and the derived PtCOMT line/s. The percentage of lateral roots covered with the fungal hyphae varied between 4.5 and 29.9 per genotype and it was significantly higher in control clone $\mathrm{A}$ than in its transgenic line $65(P=0.006)$, and also slightly higher than in line $23(P=0.054)$ (Table 2). $P$. involutus induced radial elongation of the epidermal cells in the roots of control clone A and line 65, and the fungal hyphae penetrated in most cases as far as the border of the epidermal and cortical cells and occasionally around the epidermal cells (Table 2 and Fig. 2b). In contrast, in the roots of line 23 the fungal hyphae penetrated less frequently along the radial cell walls of the epidermis (Table 2 and Fig. 2c). In line 130, some epidermal cells of the lateral roots became radially elongated even when cultivated without the fungus (Fig. 2d). The percentage of lateral roots covered by the fungus was higher in line 130 than in clone A (Table 2) but, overall, the fungus penetrated to a less-

Table 2. - Mycorrhiza formation between the Betula pendula controls or PtCOMT lines and the ectomycorrhizal fungus Paxillus involutus in vitro. The Hartig net (HN) was classified according to the depth of fungal penetration along the radial cell walls of the epidermal cells: $0=$ the fungus does not penetrate into the epidermis, $1=$ the fungus has started to penetrate between the epidermal cells, $2=$ the fungus has penetrated as far as the border of the epidermal and cortical cells, $3=$ the fungus has penetrated around the epidermal cell/s. The relative number of lateral roots covered with the fungal hyphae is given as a proportion of all lateral roots. The letters following the values denote a significant $(P<0.05)$ difference between control clones A or E5396 and the derived transgenic lines.

\begin{tabular}{|c|c|c|c|c|c|c|}
\hline \multirow{2}{*}{ Clone/Line } & \multirow{2}{*}{$\begin{array}{l}\text { Number of } \\
\text { roots }\end{array}$} & \multicolumn{4}{|c|}{$\begin{array}{c}\text { HN elassification. } \\
\% / y \text { of roots }\end{array}$} & \multirow{2}{*}{$\begin{array}{l}\text { Proportion }(\%) \text { of lateral } \\
\text { roots covered with the } \\
\text { fungal hyphae }\end{array}$} \\
\hline & & 0 & 1 & 2 & 3 & \\
\hline A clone & 15 & - & 7 & 20 & 73 & $15.6^{\mathrm{I}}$ \\
\hline 23 & 15 & - & 40 & 13 & 47 & $6.6^{ \pm}$ \\
\hline 65 & 4 & - & - & - & 100 & $4.5^{\mathrm{b}}$ \\
\hline 130 & 10 & 30 & 40 & - & 30 & $29.9^{\prime \prime}$ \\
\hline E5390 clone & 10 & 10 & - & 40 & 50 & $20.7^{\text {it }}$ \\
\hline 110 & 6 & 66.7 & - & 16.7 & 16.7 & $5.3^{\mathrm{h}}$ \\
\hline
\end{tabular}




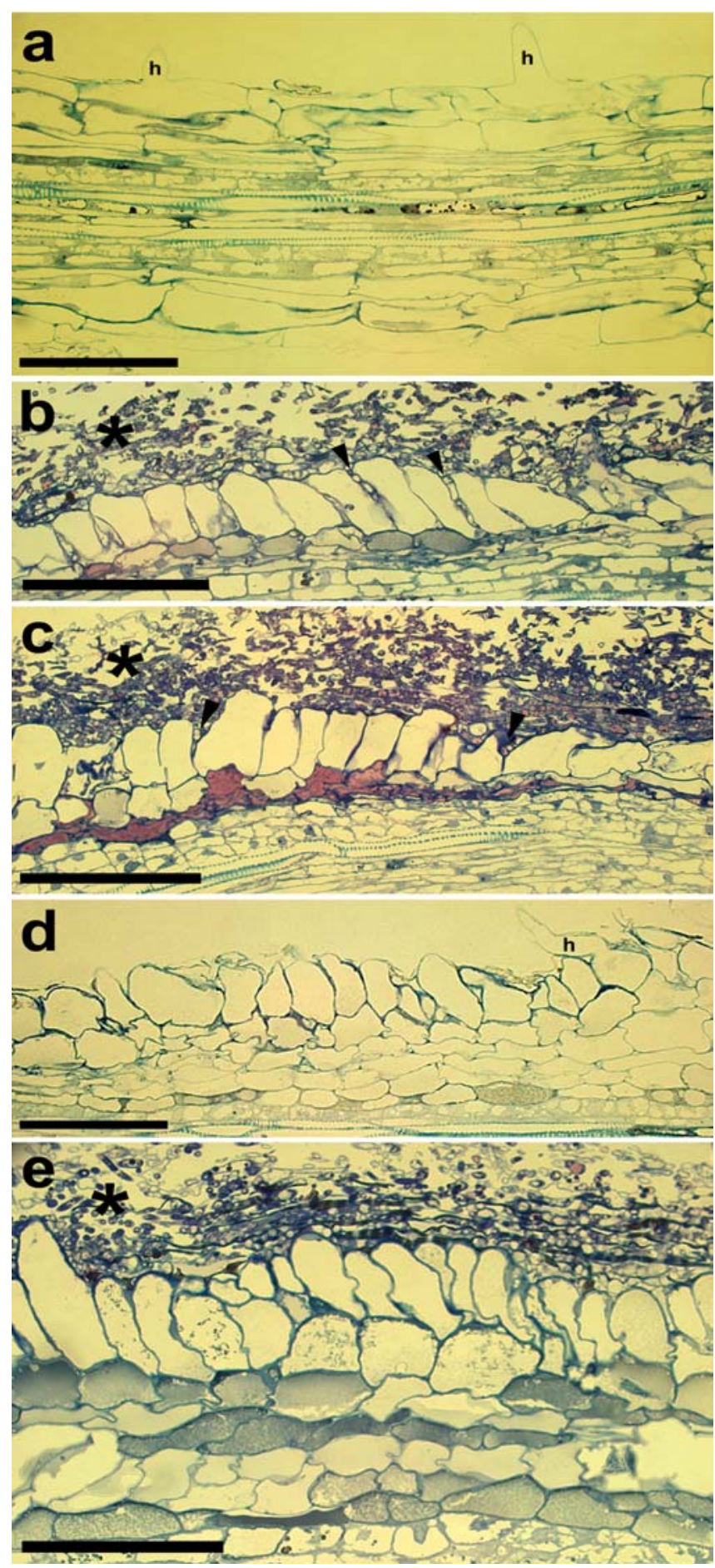

Figure 2. - The anatomical structure of non-inoculated and inoculated lateral roots of Betula pendula in vitro: (a) the noninoculated lateral root of control clone A with the epidermal cell layer containing root hairs, (b) hyphae of Paxillus involutus cover the lateral root and penetrate between the radially elongated epidermal cells of control clone A, (c) the hyphal mantle covers the radially elongated epidermal cells but the hyphae do not penetrate to an appreciable depth along the radial cell walls in the lateral root of the transgenic 35S-PtCOMT line 23 , (d) in the non-inoculated lateral root of the transgenic UbB1PtCOMT line 130 the epidermal cells show radial elongation in the absence of $P$. involutus, (e) the hyphae of $P$. involutus cover the lateral root but do not penetrate between the radially elongated epidermal cells of the lateral root of line 130. Root hairs are marked by $h$, fungal mantle by asterisks, and penetrating hyphae between the epidermal cells are indicated by arrow heads. Bars $=100 \mu \mathrm{m}$. er depth along the radial cell walls of the epidermis (Table 2 and Fig. 2e).

Control clone E5396 had a significantly $(P=0.006)$ higher percentage of lateral roots covered by the fungal hyphae than line 110 (Table 2). In the roots of clone E5396, $P$. involutus induced radial elongation of the epidermal cells and in most cases penetrated as far as the border of the epidermal and cortical cells or around the epidermal cells. In contrast, in the inoculated roots of line 110 the fungal penetration was either absent or there was only slight penetration of the fungal hyphae along the radial cell walls of the epidermis (Table 2).

\section{The root lignin $S$ / G ratio}

Due to the small amount of in vitro root material available for lignin analyses, we also determined the root lignin $\mathrm{S} / \mathrm{G}$ ratio in the non-inoculated, greenhousegrown 2- to 3-year-old plants representing the same clones and transgenic lines as used in the in vitro experiment (Table 3). Generally, the $\mathrm{S} / \mathrm{G}$ ratios were lower in the roots of the in vitro plants than in the roots of the greenhouse-grown plants. On the other hand, the low $\mathrm{S} / \mathrm{G}$ ratio found in the roots of transgenic line 23 in vitro was also evident in the roots of the greenhouse-grown plants. When the $\mathrm{S} / \mathrm{G}$ ratios were compared between the inoculated and non-inoculated roots within the $B$. pendula clone or PtCOMT line in vitro, the inoculation did not have any consistent effect on the root $\mathrm{S} / \mathrm{G}$ ratio (Table 3).

\section{Discussion}

In the present work we studied the ability of PtCOMTmodified $B$. pendula lines and non-transformed control clones to form ectomycorrhiza (ECM) with $P$. involutus in vitro. The in vitro cultivation system allowed us to characterise specific early interactions between the clones/lines and the $P$. involutus strain without interference from the multiple biotic interactions that always exist in vivo. $P$. involutus formed an ECM symbiosis with both control clones and all the PtCOMT lines but, compared to the non-transgenic control clones, the number of lateral roots covered with fungal hyphae and/or development of a Hartig net $(\mathrm{HN})$ decreased in line 23 with a reduced root lignin $\mathrm{S} / \mathrm{G}$ ratio and in lines 110 and 130 with slower adventitious root formation and changed root morphology, respectively. In another, recent study on $B$. pendula- $P$. involutus interaction, transgenic lines with disturbed root formation but showing no lignin modification were observed to form normal ECM in vitro (SEPPÄNEN et al., 2007). In the present work, $P$. involutus had in general a positive effect on the host plant in both control clones and all the transgenic lines. However, whether the positive effects were observed in shoot and root growth and/or number of viable plants was highly dependent on the clone and line.

It is well known that lignification plays a role in the reinforcement of cell walls and in the formation of an effective physical and chemical barrier to restrict pathogenic fungal penetration and infection especially (EvANS and Stephens, 1989; BuCCIARELLI et al., 1999; He et al., 
Table 3. - The syringyl/guaiacyl (S/G) ratios of root lignin of the B. pendula control clones and PtCOMT lines. In vitro plants were grown without the fungus or inoculated with the ectomycorrhizal Paxillus involutus for 8 weeks. The $\mathrm{S} / \mathrm{G}$ ratios of in vitro material are based on four independent thioasidolysis analyses, except for non-inoculated control clone A and PtCOMT lines 130 and 110 where only single analyses could be performed. Due to the limited amount of in vitro root material, the root samples from the 2- to 3-year-old non-inoculated plants growing in the greenhouse and representing the same clones and transgenic lines as in the in vitro experiment, were also analysed. For greenhouse plants, the $\mathrm{S} / \mathrm{G}$ results are based on 2 or 3 independent thioacidolysis determinations.

Root lignirs $\mathrm{S} / \mathrm{G}$

\begin{tabular}{|c|c|c|c|}
\hline \multirow{2}{*}{ Clone/Line } & \multicolumn{2}{|c|}{ in vitro plants } & \multirow{2}{*}{ Greenhouse plants } \\
\hline & Non-inoculated & lnoculated & \\
\hline A clone & 0.85 & $0.72 \pm 0.01$ & $2.6 \pm 0.09$ \\
\hline 23 & $0.41 \pm 0.01$ & $0.51 \pm 0.07$ & $0.6=0.06$ \\
\hline 65 & $0.66 \pm 0.08$ & $0.76 \pm 0.06$ & $2.7=0.25$ \\
\hline 130 & 0.80 & $0.62 \pm 0.06$ & $2.6=0.12$ \\
\hline E5396 clone & $0.64 \pm 0.02$ & $0.62 \pm 0.03$ & $2.7=0.01$ \\
\hline 110 & 0.79 & $0.89 \pm 0.08$ & $2.3=0.03$ \\
\hline
\end{tabular}

2002; HE and Wolyn, 2005). In the ECM symbiosis, on the other hand, the defence responses are thought to be weak or only transient (HAHN and MENDGEN, 2001). In a recent microarray assay of $B$. pendula-P. involutus ECMs, expression of the precursor genes of lignin biosynthesis, CCoAOMT (caffeoyl-coenzyme A 3-Omethyltransferase) and $S A D$ (sinapyl alcohol dehydrogenase), as well as a gene homolog to a dirigent protein, were induced in specific developmental phases of ECMs (LE QUÉRÉ et al., 2005). This indicates that lignin biosynthesis may also be involved in the formation of the ECM association.

In the present work, the PtCOMT modification was found to result in a decreased $\mathrm{S} / \mathrm{G}$ ratio in root lignin of transgenic line 23 compared to control clone A. This is consistent with our previous results on the lignin composition of developing xylem (ARONEN et al., 2003) and leaves (Timmonen et al., 2005) of the same line. The decrease in the $\mathrm{S} / \mathrm{G}$ ratio is assumed to follow from the suppression of $\mathrm{S}$ lignin formation (ARONEN et al., 2003). The $\mathrm{S} / \mathrm{G}$ ratios in the in vitro roots of all the transgenic and non-transgenic plants were generally low compared to that in the stem (ARONEN et al., 2003), leaf (TIIMONEN et al., 2005) and root lignin of the greenhouse-grown plants. This may potentially correspond to later formation of $\mathrm{S}$ monolignols along with plant development (SARKANEN and HERGERT, 1971; Chen et al., 2002). Line 23 with a decreased $\mathrm{S} / \mathrm{G}$ ratio was able to form ECMs with $P$. involutus in vitro but, compared to control clone $\mathrm{A}$, the number of lateral roots covered with fungal hyphae was lower and the HN was less developed. However, line 23 benefited from fungal inoculation in lateral root formation more than control clone A, which probably compensated for the reduced mycorrhiza formation and, thus, the inoculated plants of line 23 grew as well as those of clone A and transgenic line 65 .

In general, the differences in ECM formation and growth may be caused directly by the transgenes (as probably was the case in line 23) or position, epistatic or pleiotrophic effects of the transgene. In the present study, root formation of line 110 was slightly lowered and line 130 had changed root morphology due to the genetic modification, and the subsequent formation of $\mathrm{HN}$ by $P$. involutus was poor. The absence or very poor formation of the $\mathrm{HN}$ might potentially contribute to reduced nutrient exchange and, therefore, to the lack of any change in plant growth due to the inoculation. However, the number of viable plants increased the most substantially in lines 110 and 130 as a result of inoculation. This is in agreement with our earlier studies on P. sylvestris (NiEMI et al., 2000; NiEMI and HäGGMAN, 2002), in which specific ECM fungi increased the survival of the host plant even in the absence of ECMs. The benefit from the ECM fungi without mycorrhiza formation may be a result of, for example, specific plant growth regulators released by the fungus, or modification of the medium composition (reviewed by NIEMI et al., 2004). These results show the complexity of the ECM association even in the closed in vitro system without multiple biotic interactions and, therefore, highlight 
the importance of the characterisation of each control clone/transgenic line and fungus interaction already in in vitro.

Public concern regarding the safe use of genetically modified trees in practical applications such as silviculture has been faced with a lack of information about environmental aspects (HÄGGMAN et al., 2006). The forest industry has focused especially on the development of raw wood with lignin characteristics that are more suitable for pulping. At this point very little is known about the ecological interactions of trees genetically transformed with lignin biosynthesis genes. The current work describes inoculation of this kind of tree with the ECM fungus in vitro. It clearly shows that, regardless of the decreased $\mathrm{S} / \mathrm{G}$ ratio or changed root morphology compared to the control clones, all transgenic lines of $B$. pendula interacted with $P$. involutus and benefited from this association in vitro, but all in highly specific ways.

\section{Acknowledgements}

The authors are grateful to the technical personnel at the Finnish Forest Research Institute (Punkaharju and Vantaa Research Units) for their valuable contribution in the current work. The research was financed by TEKES, the National Technology Agency (Project 40481/03 to Finnish Forest Research Institute and the University of Oulu), Academy of Finland (Project 105214 to HH, 202415 and 126488 to $\mathrm{KN}$ ) and the Foundation of HEIKKI and Hilma Honkanen (grant to HT).

\section{References}

Anterola, A. M. and N. G. Lewis (2002): Trends in lignin modification: a comprehensive analysis of the effects of genetic manipulations/mutations on lignification and vascular integrity. Phytochemistry 61: 221-294.

ARonen, T., H. Timmonen, C.-J., Tsai, S. Jokipit, X. Chen, V. ChIANG and H. HägGman (2003): Altered lignin in transgenic silver birch (Betula pendula) expressing PtCOMT gene, pp 149-161. In: Sustainable forestry, wood products \& biotechnology, edited by S. EsPINEL, Y. BARREDO and E. RITTER, DFA-AFA Press, VitoriaGasteiz.

Baucher, M., C. Halpin, M. Petit-Conil and W. Boerjan (2003): Lignin: Genetic engineering and impact on pulping. Crit Rev Biochem Mol Biol 38: 305-350.

BAucher, M., B. Monties, M. VAN Montagu and W. BoerJAN (1998): Biosynthesis and genetic engineering of lignin. Crit Rev Plant Sci 17: 125-197.

Binet, M.-N., M. LePETIT, J.-H. WeIL and L.-H. TessieR (1991a): Analysis of sunflower polyubiquitin promoter by transient expression. Plant Sci 79: 87-94.

BINET, M.-N., J.-H. WEIL and L.-H. TESSIER (1991b): Structure and expression of sunflower ubiquitin genes. Plant Mol Biol 17: 395-407.

BoerJan, W., J. RALPH and M. BAUCher (2003): Lignin biosynthesis. Annu Rev Plant Biol 54: 519-546.

Brun, A., M. Chalot, R. D. Finlay and B. Söderström (1995): Structure and function of the ectomycorrhizal association between Paxillus involutus (Batsch) Fr. and Betula pendula Roth. I Dynamics of mycorrhiza formation. New Phytol 129: 487-493.
Bucciarelli, B., M. E. Ostry, R. G. Fulcher, N. A. ANDERSON and C. P. VANCE (1999): Histochemical and microspectrophotometric analyses of early wound responses of resistant and susceptible Populus tremuloides inoculated with Entoleuca mammata (=Hypoxylon mammatum). Can J Bot 77: 548-555.

Bugos, R. C., V. L. C. Chiang and W. H. Campbell (1991): cDNA cloning, sequence analysis and seasonal expression of lignin-bispecific caffeic acid/5-hydroxyferulic acid O-methyltransferase of aspen. Plant Mol Biol 17: 1203-1215.

Chen, L., C. Auh, F. Chen, X. Cheng, H. Aluoe, R. A. Dixon and Z. WANG (2002): Lignin deposition and associated changes in anatomy, enzyme activity, gene expression, and ruminal degradability in stems of tall fescue at different developmental stages. J Agric Food Chem 50: 5558-5565.

Chiang, V. L. and M. Funaoka (1990): The dissolution and condensation reactions of guaiacyl and syringyl units in residual lignin during kraft delignification of sweetgum. Holzforschung 44: 147-155.

Evans, T. A. and C. T. StePhens (1989): Increased susceptibility to Fusarium crown and root rot in virus-infected asparagus. Phytopathology 79: 253-258.

HägGman, H., K. Niemi, H. Timmonen, T. Ylioja and V. CHIANG (2006): Environmental aspects of lignin modified trees, pp 105-122. In: Tree transgenesis: Recent developments, edited by FLADUNG, M. and D. EwALD, Springer-Verlag, Berlin Heidelberg.

Hahn, M. and K. Mendgen (2001): Signal and nutrient exchange at biotrophic plant-fungus interfaces. Curr Opin Plant Biol 4: 322-327.

HALPIN, C. and W. BOERJAN (2003): Stacking transgenes in forest trees. Trends Plant Sci 8: 363-365.

Halpin, C., S. C. Thain, E. L. Tilston, E. Guiney, C. LAPIERRE and D. W. HoPKINS (2007): Ecological impacts of trees with modified lignin. Tree genetics \& Genomes 3: 101-110.

He, C. Y., T. HsIANG and D. J. Wolyn (2002): Induction of systemic disease resistance and pathogen defence responses in Asparagus officinalis inoculated with nonpathogenic strains of Fusariun oxysporum. Plant Pathol 51: 225-230.

He, C. Y. and D. J. Wolyn (2005): Potential role for salicylic acid in induced resistance of asparagus roots to Fusarium oxysporum f.sp. asparagi. Plant Pathol 54: 227-232.

Heinonen-TANski, H. and T. Holopainen (1991): Maintenance of ectomycorrhizal fungi, pp 413-422. In: Methods in Microbiology Vol 23, edited by NorRIS, J. R., D. J. READ and A. K. VARNA, Academic Press, London.

Higuchi, T. (1985): Biosynthesis of lignin, pp 141-160. In: Biosynthesis and biodegradation of wood components, edited by HiguchI, T., Academic Press, New York.

Hoffman, L., S. Besseau, P. Geoffroy, C. Ritzenthaler, D. Meyer, C. Lapierre, B. Pollet and M. Legrand (2004): Silencing of hydroxycinnamoyl-coenzyme A shikimate/quinate hydroxycinnamoyltransferase affects phenylpropanoid biosynthesis. Plant Cell 16: 1446-1465.

JENTSchKe, G., S. Winter and D. L. GodBold (1999): Ectomycorrhizas and cadmium toxicity in Norway spruce seedlings. Tree Physiol 19: 23-30.

Johansson, T., A. Le Quéré, D. Ahren, B. Söderström, R. ERLANDSSON, J. LundeBERG, M. UhlÉN and A. Tunlid (2004): Transcriptional responses of Paxillus Involutus and Betula pendula during formation of ectomycorrhizal root tissue. Mol Plant-Microbe Interact 17: 202-215. 
Le Quéré, A., D. P. Wright, B. Söderström, A. Tunlid and T. JoHANsson (2005): Global patterns of gene regulation associated with the development of ectomycorrhiza between birch (Betula pendula Roth.) and Paxillus involutus (Batsch) Fr. Mol Plant-Microbe Interact 18: 659-673.

LI, L., S. LU and V. ChIANG (2006): A genomic and molecular view of wood formation. Crit Rev Plant Sci 25: 215-233.

Lindahl, B. O., A. F. S. TAYLOR and R. D. Finlay (2002): Defining nutritional constraints on carbon cycling in boreal forests - towards a less 'phytocentric' perspective. Plant Soil 242: 123-135.

LlOYD, G. and B. McCown (1980): Commercially-feasible micropropagation of Mountain Laurel, Kalmia latifolia, by use of shoot-tip culture. Int Plant Prop Soc Proc 30: 421-427.

MARX, D. H. (1969): The influence of ectotrophic fungi on the resistance of pine roots to pathogenic infections. I. Antagonism of mycorrhizal fungi to root pathogenic fungi and soil bacteria. Phytopathology 59: 153-163.

Morel, M., C. JACOB, A. KOHLER, T. JOHANSSON, F. Martin, M. Chalot and A. Brun (2005): Identification of genes differentially expressed in extraradical mycelium and ectomycorrhizal roots during Paxillus involutus-Betula pendula ectomycorrhizal symbiosis. Appl Environ Microbiol 71: 382-391.

Morin, C., J. SAmson and M. Dessureault (1999): Protection of black spruce seedlings against Cylindrocladium root rot with ectomycorrhizal fungi. Can $\mathrm{J}$ Bot $\mathbf{7 7}$ : 169-174.

Niemi, K. and H. HÄGGMan (2002): Pisolithus tinctorius promotes germination and forms mycorrhizal structures in Scots pine somatic embryos in vitro. Mycorrhiza 12: 263-267.

NiEMI, K., H. HÄGGMAN and T. SARJALA (2002): Effects of exogenous diamines on the interaction between ectomy- corrhizal fungi and adventitious root formation in Scots pine in vitro. Tree Physiol 22: 373-381.

Niemi, K., M. Salonen, A. Ernstsen, H. Heinonen-Tanski and H. HÄGGMAN (2000): Application of ectomycorrhizal fungi in rooting of Scots pine fascicular shoots. Can J For Res 30: 1221-1230.

NiEMI, K., C. SCAGEL and H. HÄGGMAN (2004): Application of ectomycorrhizal fungi in vegetative propagation of conifers. Plant Cell Tissue Organ Cult 78: 83-91.

Pilate, G., E. Guiney, K. Holt, M. Petit-Conil, C. Lapierre, J.-C. Leplé, B. Pollet, I. Mila, E. A. WebSter, H. G. Marstorp, D. W. Hopkins, L. Jouanin, W. Boeruan, W. Schuch, D. Cornu and C. Halpin (2002): Field and pulping performances of transgenic trees with altered lignification. Nat Biotechnol 20: $607-612$

Rolando, C., B. Monties and C. LAPIERRE (1992): Thioacidolysis, pp 334-349. In: Methods in lignin chemistry, edited by Lin, S. Y. and C. W. Dence, Springer-Verlag, Berlin.

SARKANEN, K. V. and H. L. Hergert (1971): Classification and distribution, pp 43-94. In: Lignins: Occurrence, formation, structure and reaction, edited by SARKANEN, K. V. and C. H. Ludwig, Wiley-Interscience, New York.

Seppänen, S.-K., H.-L. Pasonen, S. Vauramo, J. Vahala, M. Toikka, I. KilpeläInen, H. SetÄLÄ, T. H. TeERI, S. Timonen and A. PAPPINEN (2007): Decomposition of the leaf litter and mycorrhiza forming ability of silver birch with a genetically modified lignin biosynthesis pathway. Appl Soil Ecol 36: 100-106.

SMITH, S.E. and D. J. READ (1997): Mycorrhizal symbiosis. $2^{\text {nd }}$ ed, Academic Press, San Diego.

Timonen, H., T. Aronen, T. LaAkso, P. SaranpäÄ, V. ChiANG, T. Ylioja, H. Roininen and H. HäGgMan (2005): Does lignin modification affect feeding preference or growth performance of insect herbivores in transgenic silver birch (Betula pendula Roth)? Planta 222 699-708.

\title{
Genetic Diversity of the Relict Plant Taiwania cryptomerioides Hayata (Cupressaceae) in Mainland China
}

\author{
By Zhong-Chao Li ${ }^{1)}$, XIAo-LAN $\mathrm{WANG}^{2)}$ and Xue-Jun GE ${ }^{1), *)}$
}

(Received 26 ${ }^{\text {th }}$ April 2006)

\begin{abstract}
The genetic diversity and differentiation of five populations of Taiwania cryptomerioides Hayata in mainland China were investigated using inter-simple sequence

1) South China Botanical Garden, The Chinese Academy of Sciences, Guangzhou 510650, P. R. China.

2) Center for Functional Genomics and Microarray, Guangzhou University, Guangzhou 510405

*) Corresponding author: Dr. XuE-Jun GE. South China Botanical Garden, The Chinese Academy of Sciences, Guangzhou 510650, P. R. China. Tel: +86-20-3725 2551; Fax: +86-20-3725-2831. Email address: gexuejun@mail.sysu.edu.cn, xjge@scbg.ac.cn
\end{abstract}

repeats (ISSR). In comparison with other coniferous species, T. cryptomerioides from mainland China possesses little genetic variation, particularly at the level of individual populations (the percentage of polymorphic loci, Nei's gene diversity and Shannon's indices of diversity at the species and population levels are $38.02 \%$, $0.1326,0.1986$ and $9.27 \%, 0.035,0.0518$ respectively). In contrast, the level of population differentiation is much higher $\left(\mathrm{G}_{\mathrm{ST}}: 0.7269\right.$; Shannon's genetic differentiation: 0.7392; Hickory $\theta^{B}: 0.668$; AMOVA genetic differentiation: $72.37 \%$ ). The genetic divergence of pairs of populations was not significantly correlated with the geographical distance separating them. Current patterns of 